\title{
MACROCRIMINALIDADE E CRIMINALIDADE ESTRUTURAL/CULTURAL: UMA LEITURA DA "NOVA" CATEGORIA DE MACROCRIMINALIDADE A PARTIR DE PIERRE BOURDIEU
}

\author{
Macrocriminality and structural criminality: an interpretation of the "new" \\ category of macrocriminality, according to Pierre Bourdieu
}

José Edilson da Cunha Fontenelle Neto

Resumo: O presente trabalho tem por escopo demonstrar, de forma breve porém séria, a macrocriminalidade enquanto fenômeno estrutural e estruturante das práticas que envolvem o exercício dos poderes na sociedade contemporânea, mormente dentro do cenário eleitoral, vislumbrando os espaços de poder - constitucionalmente desenhados para servirem ao interesse público - sendo utilizados para fins pessoais, violando-se, em consequência, os princípios reitores da administração pública, sobretudo no que tange à moralidade e à impessoalidade. Nesse sentido, foram perquiridos meios adequados ao combate das práticas macrocriminosas, sobretudo por meio da redução dos espaços de poder discricionário, tal qual assenta Luigi Ferrajoli. Portanto, com o presente trabalho buscou-se evidenciar a importância do controle dos espaços de poder de todo aquele que, em nome do Estado, o exerce, enquanto forma de garantia individual e coletiva.

Palavras-chave: Macrocriminalidade. Criminalidade estrutural. Poder discricionário. Impessoalidade.

\begin{abstract}
The present work aims to demonstrate, briefly but seriously, macrocrime as a structural and structuring phenomenon of practices involving the exercise of powers in contemporary society, especially in cases of electoral crimes and related ones, seeing the spaces of power, constitutionally designed to serve the public interest, been neglected for reasons of personal nature, violating the governing principles of public administration, especially with regard to morality and impersonality. In this sense, legitimate and adequate means of combating macro-criminal practices were sought, especially by reducing the spaces of discretionary power, as Luigi Ferrajoli bases. Therefore, the present work sought to highlight the importance of controlling the power spaces of all those who, in the name of the State, exercise it, as a means of individual and collective guarantee, once society is protected against macro-criminal practices. Keywords: Macro-crime. Structural crime. Discretionary power. Impersonality.
\end{abstract}




\section{Introdução}

Fato é que, historicamente, o sistema de controle social penal (e o chamo assim porque este não se limita ao direito penal, indo além: processo penal, execução penal, etc.) foi um instrumento destinado às classes menos favorecidas e desprovidas de posses, servindo como um instrumento de defesa das classes hegemônicas contra os desvios dos desapossados, como há muito aponta a criminologia crítica ${ }^{1}$.

Assim, em suma, o Direito Penal tinha como escopo tutelar o patrimônio individual em detrimento dos desvios individuais.

Ocorre que com o advento da Constituição, e mais, com a evolução do direito, que passou a se ocupar dos bens coletivos lato sensu, passou-se a vislumbrar que deveria ser dada importância a outras práticas criminosas, sobretudo àquelas que eram praticadas por indivíduos das classes hegemônicas e que tinham como sujeitos passivos a coletividade, ou seja, os direitos coletivos sticto sensu e difusos.

A esse gênero de criminalidade, cuja criminalidade eleitoral espécie foi denominada macrocriminalidade, assunto que será objeto do presente artigo.

Desse modo, a hipótese principal do trabalho é a de que a macrocriminalidade pode ser vista e analisada como uma forma de criminalidade estrutural, a partir das categorias e dos conceitos de Pierre Bourdieu, haja vista que, em hipótese, pode ser esta criminalidade vislumbrada como uma estrutura social (re)produtora de si mesma.

Sendo assim, a partir de tal leitura, será possível vislumbrar-se instrumentos (mais) efetivos e eficazes ao seu combate, a fim de tornar as dinâmicas sociais menos passíveis destes desvios.

Para realização desta análise do sistema e das formas mais adequadas de controle, será o trabalho elaborado em quatro capítulos subsequentes a esta introdução, seguidos das considerações finais.

No segundo capítulo, buscar-se-á discorrer sobre o conceito de macrocriminalidade, no que consiste tal categoria, quais bens jurídicos busca tutelar.

Em seguida, no terceiro capítulo, será buscada a análise sobre as categoriais bourdieuanas de estrutura (estruturante e estruturada), a fim de conceituar operacionalmente, a partir deste marco teórico, a categoria criminalidade estrutural.

${ }^{1}$ CIRINO DOS SANTOS, Juarez. Direito penal parte geral. 5. ed. Florianópolis: Conceito Editorial, 2012. 
Seguindo ao quarto capítulo, este buscará abordar, de forma analítica, quais práticas sociais podem ser abarcadas pela categoria macrocriminosas e que, portanto, devem ser combatidas.

Então, no quinto capítulo, será realizada uma abordagem sobre as formas de serem evitadas tais práticas, o que será realizado a partir de uma leitura garantista Ferrajoliana ${ }^{2}$.

Na metodologia do presente trabalho, foi utilizado o método indutivo na fase de investigação; na fase de tratamento de dados, o método cartesiano; e no relatório da pesquisa, foi empregada a base indutiva. Foram também acionadas as técnicas do referente ${ }^{3}$, da categoria ${ }^{4}$, dos conceitos operacionais $^{5}$, da pesquisa bibliográfica ${ }^{6}$ e do fichamento ${ }^{7}$.

\section{Macrocriminalidade}

Macrocriminalidade se trata de um conceito relativamente novo, que veio para substanciar, categorizar", parte dos chamados "crimes do colarinho branco" (White Collar Crimes). Ou seja, os crimes decorrentes da chama- da macrocriminalidade são espécies do gênero "crimes do colarinho branco", delitos estes em regra praticados por pessoas das camadas sociais mais altas.

${ }^{2}$ FERRAJOLI, Luigi. Direito e razão: teoria do garantismo penal. 3. ed. (Trad.) SIZA,
Ana Paulo Zomer; CHOUKR, Fauzi Hassan; TAVARES, Juares; GOMES, Luiz Flávio.
São Paulo: Revista dos Tribunais, 2010 .
3 “explicitação prévia do motivo, objetivo e produto desejado, delimitado o alcance temáti-
co e de abordagem para uma atividade intelectual, especialmente para uma pesquisa”. PA-
SOLD, Cesar Luiz. Prática da Pesquisa Jurídica e metodologia da pesquisa jurídica.
Florianópolis: OAB/SC Editora, 2007, p. 241.
4 “palavra ou expressão estratégica à elaboração e/ou expressão de uma ideia”. PASOLD, Cesar
Luiz. Prática da Pesquisa Jurídica e metodologia da pesquisa jurídica, p. 229.
5 “definição estabelecida ou proposta para uma palavra ou expressão, com o propósito
de que tal definição seja aceita para os efeitos das ideias expostas”. PASOLD, Cesar Luiz. Prática da Pesquisa Jurídica e metodologia da pesquisa jurídica, p. 229.

6 “Técnica de investigação em livros, repertórios jurisprudenciais e coletâneas legais". PASOLD, Cesar Luiz. Prática da Pesquisa Jurídica e metodologia da pesquisa jurídica, p. 240.

7 “Técnica que tem como principal utilidade otimizar a leitura na Pesquisa Científica, mediante a reunião de elementos selecionados pelo Pesquisador que registra e/ou resume e/ ou reflete e/ou analisa de maneira sucinta, uma Obra, um Ensaio, uma Tese ou Dissertação, um Artigo ou uma aula, segundo Referente previamente estabelecido". PASOLD, Cesar Luiz. Prática da Pesquisa Jurídica e metodologia da pesquisa jurídica, p. 233.

${ }^{8}$ PASOLD, Cesar Luiz. Metodologia da Pesquisa Jurídica: Teoria e Prática. 12 ed. rev. São Paulo: Conceito Editorial, 2011, p. 59. 
Os delitos da chamada macrocriminalidade, então, seriam os casos em que há apropriação das coisas comuns/públicas, tratam-se, assim, de apropriação das res públicas (coisas públicas). Os sujeitos passivos dos delitos, portanto, são indeterminados, ou melhor, são todos que não sejam os sujeitos ativos.

O ponto nevrálgico da macrocriminalidade, todavia, é que estes delitos possuem sujeitos passivos indeterminados, sendo indeterminados, inclusive, na maioria das vezes, a própria abrangência do delito, sendo fato, contudo, que os agentes das classes menos favorecidas serão os principais lesados, haja vista que estes sofrem, de forma mais gravosa, os ônus dos serviços públicos deficitários.

Portanto, é possível se sustentar que, considerando os crimes patrimoniais da microcriminalidade, onde, em regra, os agentes das classes subalternas pratica(va)m delitos contra os indivíduos das classes hegemônicas $^{9}$, na macrocriminalidade há uma inversão, sendo os agentes das classes hegemônicas que, em regra, praticarão atos desviantes que lesarão as classes menos abastadas.

Assim, em regra, os crimes envolvendo a macrocriminalidade não são assim vistos ou classificados em razão dos tipos penais em espécie, mas, sim, em consonância com o bem jurídico e os sujeitos passivos afetados.

Dessarte, ciente de que os direitos políticos e eleitorais (arts. 14 a 16, da CRFB/88) e processuais penais ${ }^{10}$ são expressões máximas da democracia e, portanto, também, dos direitos difusos e coletivos, é que se mostra tão imbricada a relação entre Justiça Eleitoral e macrocriminalidade.

Nesse sentido, o Supremo Tribunal Federal, nos autos do Inquérito n. $4435^{11}$, decidiu - de forma bastante acertada, diga-se de passagem - que a competência para julgar crimes eleitorais e conexos são da competência da Justiça Eleitoral.

\footnotetext{
${ }^{9}$ SANTOS, Juarez Cirino dos. Direito Penal: parte geral. 5. ed. Santa Catarina: Conceito, 2012, p. 442/454.

${ }^{10}$ GOLDSCHIMIDT, James. Problemas jurídicos y políticos del proceso penal, Buenos Aires: AJEA, 1936, p. 67: "Los princípios de la poítica procesal de uma nación no son otra cosa que segmentos de su política estatal em general. Se puede decir que la estructura del proceso penal de una nación no és sino el termómetro de los elementos corporativos ou autoritarios de su Constitución"

${ }^{11}$ BRASIL. Supremo Tribunal Federal. Inquérito nº4435. Relator: Ministro Marco Aurélio. Brasília, DF, 14 de março de 2019. Diário Oficial da União.
} 
Desse modo, inequívoco o fato de que restou à Justiça Eleitoral o papel de julgar (não acusar e tampouco combater) a macrocriminalidade envolvendo a seara eleitoral.

\section{Criminalidade estrutural: o campo criminoso enquanto estrutura estruturante e estruturada}

Se fato é que a macrocriminalidade é expressão da apropriação da coisa coletiva/pública (res pública), se faz imprescindível para o combate efetivo a estas práticas categoricamente antirrepublicanas a sua análise a partir das estruturas de poder que envolvem tal criminalidade.

Afinal, muito mais do que figuras criminosas, por detrás da $m a-$ crocriminalidade há uma verdadeira cultura da vantagem individual em detrimento do coletivo (o famoso "jeitinho brasileiro").

Assim sendo, em razão das relações de poder que envolvem a macrocriminalidade, estas podem ser vistas como estruturas estruturantes e estruturadas de dominação, através da acumulação e da maximização do capital simbólico ${ }^{12}$, político e econômico ${ }^{13}$.

Nesse sentido, adequada a análise da sociologia das práticas de Pierre Bourdieu, para quem as dinâmicas sociais de poder dar-se-iam por meio de sistemas de comunicação, que são estruturas, a um só tempo, estruturantes e estruturadas de tráfego de capital simbólico.

As relações de comunicação são, de modo inseparável, sempre, relações de poder que dependem, na forma ou no conteúdo, do poder material ou simbólico acumulado pelos agentes (ou pelas instituições) envolvidas nessas relações e que, como o dom ou o potlatch, podem permitir acumular poder simbólico. (p. 11)

Quanto a característica estruturante, diz-se ser assim porque estruturam o comportamento futuro, por meio das dinâmicas e, até mesmo, das pré-compreensões dos sujeitos.

${ }^{12}$ BOURDIEU, Pierre. Razões práticas: sobre a teoria da ação. Tradução Mariza Corrêa. São Paulo: Papirus, 1996, p. 107: “O Capital simbólico é uma propriedade qualquer (de qualquer tipo de capital, físico econômico, cultural, social), percebida pelos agentes sociais cujas categorias de percepção são tais que eles podem entendê-las (percebê-las) e reconhecê-las, atribuindo-lhes valor".

${ }^{13}$ BOURDIEU, Pierre. Choses dites. Paris: Les Éditions de Minuit, 1987, p. 33; Bourdieu, Pierre. Questions de sociologie. Paris: Les Éditions de Minuit, 1984, 1984, p. 114. 
Já por estruturadas, porque são compostas (estruturadas) de uma certa forma, de um certo modo, ainda que não estanque e hermético, mas, sim, passível de modificação, inclusive pela atuação dos agentes de seu meio (e aqui, possivelmente, temos uma solução ao nosso problema).

Sobre o assunto, melhor ensina BOURDIEU:

Os <<sistemas simbólicos $>>$, como instrumentos de conhecimento e de comunicação, só podem ser estruturantes porque são estruturados. O poder simbólico é um poder de construção da realidade que tende a estabelecer uma ordem gnoseológica: o sentido imediato de mundo (e, em particular, do mundo social) supõe aquilo que Durkheim chama de conformismo lógico, quer dizer, <<uma concepção homogênea do tempo, do espaço, do número, da causa, que torna possível a concordância entre as inteligências $>{ }^{14}$.

Portanto, se passamos a entender as dinâmicas práticas enquanto sistema estruturante/estruturado, é possível vislumbrar(mos) os sistemas, os métodos e modos de ser, da macrocriminalidade como tal.

Ou seja, é possível uma leitura sociológica dos espaços de poder em que há apropriação da coisa pública (res pública), afinal, tais espaços, em regra, são campos de poder estruturados (de certa forma não republicana) e que, desse modo, estruturam os sujeitos que ali ingressam, fazendo com que estes lutem dentro de seus respectivos campos de atuação para acumulação, manutenção e maximização de seus capitais simbólicos, político e econômico. Nada mais Bourdieuano.

Nesse sentido, a prática cotidiana das relações da dinâmica eleitoral e política são relações que se desenvolvem em uma determinada estrutura (estruturante e estruturada).

Ocorre, contudo, que as relações econômicas e políticas sempre tiveram sobremaneira correlação, havendo nitidamente uma interdependência entre modelo econômico vigente e modelo político.

Nesse sentido, destaca BOURDIEU ${ }^{15}$ :

As facções dominantes, cujo poder assenta no capital econômico, têm em vista impor a legitimidade da sua dominação quer por meio

\footnotetext{
${ }^{14}$ BOURDIEU, Pierre. O poder simbólico. Lisboa: Difusão Editorial Ltda, 1989, p. 09.

${ }^{15}$ BOURDIEU, Pierre. O poder simbólico. Lisboa: Difusão Editorial Ltda, 1989, p. 12.
} 
da própria produção simbólica, quer por intermédio dos ideólogos conservadores, os quais só verdadeiramente servem aos interesses dos dominantes por acréscimo.

Assim, convergindo os pensamentos, é possível afirmar(mos) que as relações de poder político e eleitoral são de um campo estruturado, que exige, de seus atores, capital simbólico político e econômico.

O ponto nevrálgico, contudo, é que os agentes que se encontram nesse campo visam à maximização e à acumulação de seus capitais simbólicos, políticos e econômicos, acumulação esta que só será possível se as condições da estrutura assim o permitirem.

Assim, a ideia de acumulação de capital social, em síntese, terá a tendência de criar superestruturas, tal qual as já indicadas por Marx ${ }^{16}$; contudo, estas terão o condão de aumentar o capital.

Sobre o assunto, é de BOURDIEU:

Abandonar a dicotomia do econômico e do não econômico que proíbe apreender a ciência das práticas "econômicas" como caso particular de uma ciência capaz de tratar todas as práticas, inclusive aquelas que se reivindicam desinteressadas ou gratuitas, portanto libertadas da "economia" como práticas econômicas, orientadas para a maximização do lucro material ou simbólico ${ }^{17}$.

Portanto, enquanto campo estruturado, a partir da análise que BOURDIEU faz da sociologia das práticas, pode ser afirmado que o jogo político e eleitoral (incluindo-se, sobretudo, as decisões administrativas, legislativas e judiciais que envolvem essas relações) é um ethos estruturado, composto pelas relações interpessoais dos indivíduos que buscarão a maximização de seus ganhos pessoais.

Já no que tange a questão estruturante, é possível se vislumbrar que essas relações de ganhos individuais em detrimento do coletivo são colocadas aos indivíduos que ingressam no ethos, de modo a tornar esses "novos" integrantes da estrutura replicadores das práticas então vigentes.

\footnotetext{
${ }^{16}$ MARX, Karl. Contribuición a la crítica de la economia politica. La Habana, Instituto do Libro, 1975, p. 10.

${ }^{17}$ BOURDIEU, Pierre. Razões práticas: sobre a teoria da ação. Tradução Mariza Corrêa. São Paulo: Papirus, 1996, p. 209
} 
Assim, as práticas de ganho individual em detrimento do coletivo, e em violação, portanto, aos princípios republicanos e da administração pública (art. 37 da CRFB/88), ganham forma de estrutura estruturante e estruturada, criando uma forma de macrocriminalidade estrutural.

\section{Práticas sociais da estrutura macrocriminosa}

Uma vez vislumbrado o fenômeno da macrocriminalidade como uma estrutura de práticas sociais, é necessário questionar quais seriam as práticas que, em regra, tendem a sobrepor os interesses individuais aos interesses privados, criando, assim, uma estrutura macrocriminosa (macrocriminalidade estrutural).

Fato é que a constatação destas práticas não é tarefa fácil, haja vista que estas sempre buscam ser encobertas por atos lícitos, o que se pode perceber é que, em regra, a apropriação da coisa pública se dá de quatro diferentes formas: a) contratação de servidores com sobrepreço e apropriação de valores (prática denominada de "rachadinha"); b) contratações de serviços com sobrepreço e apropriação de valores ("superfaturamento"); c) cargos públicos ou benefícios nesses cargos em troca de favores pessoais individuais; e d) favores pessoais em troca de dívidas pessoais e morais ao indivíduo ${ }^{18}$.

Quanto às práticas de contratação com sobrepreço, é possível verificar-se a violação dos princípios administrativos da moralidade, que se traduz no zelo com a coisa pública ${ }^{19}$ e na impessoalidade (afinal, para haver a devolução dos valores, pessoa determinada há de ser contratada), razão pela qual o ato é, sempre, administrativamente ilícito, além de criminoso.

${ }^{18}$ BORGES, Manoela. Cassado mandato do vereador Cláudio Duarte (PSL), em plenário na Câmara Municipal de BH. Disponível em <https://g1.globo.com/mg/ minas-gerais/noticia/2019/08/01/cassado-mandato-do-vereador-claudio-duarte-psl-em-plenario-na-camara-municipal-de-belo-horizonte.ghtml>. Acesso em 16 de ago. de 2019; VASSALO, Luiz; MACEDO, Fausto. Promotoria não acredita que Queiroz possa ser o líder da organização criminosa. Disponível em <http://www.tribunadainternet.com.br/promotoria-nao-acredita-que-queiroz-possa-ser-o-lider-da-organizacao-criminosa/>.Acesso em: 16 de agosto de 2019; BASTOS, Larissa. Crime aconteceu em 2014 e foi denunciado pelo Ministério Público; pena foi fixada em 12 anos e três meses. Disponível em <https:// gazetaweb.globo.com/portal/noticia/2019/04/vereador-e-condenado-a-prisao-por-oferecer-sexo-a-menor-em-troca-de-favores_74281.php>. Acesso em: 16 de ago. de 2019.

${ }^{19}$ DI PIETRO, Maria Sylvia Zanella. Direito Administrativo. 27. ed. São Paulo: Atlas, 2014, p. 77-80. 
Já no que concerne aos atos de contratação de indivíduos para cargos públicos antevendo benefícios privados, é nítida a violação da impessoalidade, uma vez que o agente público, ao contratar um indivíduo pensando em seu benefício pessoal, não está agindo sob o manto da impessoalidade, afinal, quem contrata o servidor é o órgão público, jamais a pessoa física que o representa.

Sobre o assunto, assenta a doutrina sobre a impessoalidade:

Exigir impessoalidade da administração tanto pode significar que esse atributo deve ser observado em relação aos administrados como à Administração. No primeiro sentido, o princípio estaria relacionado com a finalidade pública que deve nortear toda a atividade administrativa. Significa que a Administração não pode atuar com vistas a prejudicar ou beneficiar pessoas determinadas, uma vez que é sempre o interesse público que tem que nortear o seu comportamento. Aplicação desse princípio encontra-se, por exemplo, no artigo 100 da Constituição, referente aos precatórios judiciais; o dispositivo proíbe a designação de pessoas ou de casos nas dotações orçamentárias e nos créditos abertos para esse fim ${ }^{20}$.

Assim como já dizia o arquiteto Ludwig Mies van der Rohe, "Deus mora nos detalhes", tal qual o ponto em comum de todas as práticas acima mencionadas, que é o poder discricionário, não vinculado. Ou seja, a fonte de conluio entre o capital político e o econômico para, juntos, maximizarem-se, dá-se nos espaços de poder discricionário, por meio da violação dos princípios administrativos e republicanos, sobretudo no que tange a impessoalidade e a moralidade, razão pela qual é por este caminho que se faz necessário pensar(mos) as possíveis soluções.

\section{Possíveis soluções para a macrocriminalidade: redução dos espaços de poder (voltamos ao garantismo de Luigi Ferrajoli)}

Conforme já visto anteriormente, o desvio dos princípios republicanos para fins de apropriação privada das coisas públicas (res publica) se dá nos espaços de poder discricionário e não vinculado.

${ }^{20}$ DI PIETRO, Maria Sylvia Zanella. Direito Administrativo. 27. ed. São Paulo: Atlas, 2014, p. 68. 
Assim, a primeira possível solução para a problemática em questão seria, nessa ótica, a redução dos espaços de poder discricionário, que não deve ser a volta do positivismo exegético (já que impossível a eliminação completa dos espaços de discricionariedade), mas, sim, a adoção de um modelo garantista, tal qual o sustentado por Luigi Ferrajoli.

Sobre o assunto, ensina o mencionado autor:

Estes três significados de "garantismo", para os quais até agora forneci uma conotação exclusivamente penal, têm, a meu ver, um alcance teórico e filosófico geral que merece, pois, ser explicado. Eles delineiam, precisamente, os elementos de uma teoria geral do garantismo: o caráter vinculado do poder público no Estado de direito. (...).

O termo "Estado de direito" é aqui empregado no segundo destes dois significados; e neste é sinônimo de "garantismo". Designa, por este motivo, não simplesmente um "Estado legal" ou "regulado pelas leis", mas um modelo de Estado nascido com as modernas Constituições e caracterizado: a) no plano formal pelo princípio da legalidade, por força do qual todo poder público - legislativo, judiciário e administrativo - está subordinado às leis gerais e abstratas que lhes disciplinam as formas de exercício e cuja observância é submetida a controle de legitimidade (...); b) no plano substancial da funcionalização de todos os poderes à garantia dos direitos fundamentais dos cidadãos, por meio da incorporação limitadora em sua constituição dos deveres públicos $(\ldots)^{21}$.

Não se está a falar em eliminação dos espaços de poder discricionário, até mesmo porque estes são ínsitos ao campo jurídico e do setor público, mas, sim, em atenuá-los, reduzindo-os ao mínimo possível.

Nesse sentido, ao serem atenuados os espaços de poder discricionário e não vinculado ter-se-iam reduzidas as possibilidades de (ab)uso do capital político para fins de angariar capital econômico e simbólico.

Desse modo, a própria estrutura do ethos em que se dão as dinâmicas sociais políticas e eleitorais minorariam as possibilidades de maximização dos capitais políticos, econômicos e sociais por meios ilícitos.

${ }^{21}$ FERRAJOLI, Luigi. Direito e razão: teoria do garantismo penal. 3. ed. Tradução por SIZA, Ana Paulo Zomer; CHOUKR, Fauzi Hassan; TAVARES, Juares; GOMES, Luiz Flávio. São Paulo: Revista dos Tribunais, 2010, p. 788-790. 
Contudo, fato é que somente a atenuação dos espaços de poder discricionário, por si só, não solucionam completamente o problema, sobretudo em razão de, como dito, sempre haver algum espaço de poder discricionário.

Assim, faz-se imprescindível a adoção de medidas para os casos em que haja a prática de condutas ilícitas nestes campos de atuação públicos.

Todavia, fato é que as apropriações das coisas públicas (res pública), em regra, beneficiam todos aqueles que interagem de forma mais imediata no campo (todos aqueles que têm conhecimento da situação).

Afinal, diferentemente da microcriminalidade, em que há a figura da vítima bem delineada, como aquele que tem seu bem jurídico pessoal lesado, na macrocriminalidade as vítimas (sociedade) sequer tem ciência de que estão sendo vítimas, motivo pelo qual se torna dificultoso até mesmo o conhecimento das autoridades responsáveis pela repressão destas à sua ciência.

Assim, nos contextos macrocriminosos, em regra, tem-se "a dificuldade da Justiça Penal em recair sempre sobre os peixes pequenos ou soldados da organização, encarregados do serviço sujo, como os transportadores de droga, enquanto os mandantes restam protegidos pelo manto da organização lícita ou com aparência de lícita"22.

Portanto, a criação e o incentivo de instrumentos de colaboração premiada se mostram fundamentais para a consecução dos objetivos de reprimir a macrocriminalidade, tais como os institutos da delação premiada, do whistleblower, ou mesmo da possibilidade de ser alargado o rol dos legitimados para ajuizamento de ação civil pública, sendo pagos por meio de parte dos valores recuperados/obtidos.

Seria uma forma de, simultaneamente, combater a macrocriminalidade e reduzir a sua eficácia estruturante, haja vista a atenuação da confiança entre os agentes delituosos.

Contudo, importante destacar que todos esses institutos de colaboração premiada devem, também, possuir o mínimo possível de espaço de poder discricionário, havendo a necessidade de vinculação dos atos a serem realizados e, sobretudo, dos benefícios a serem outorgados, caso contrário, estar-se-á a transferir, a estrutura da macrocriminalidade a um outro campo de atuação, ao invés de, como deve ser, atenuá-la.

${ }^{22}$ GONÇALVES, Victor Eduardo Rios; BALTAZAR JÚNIOR, José Paulo. Legislação penal especial. 2. ed. São Paulo: Saraiva, 2016, p. 651. 
Afinal, deve-se sempre desconfiar do poder e, por isso, controlá-lo, uma vez que o "pressuposto de todo totalitarismo é uma visão finalista e otimista do poder como bom ou, seja como for, dotado de valor ético, graças à fonte de legitimação que o detém"23, enquanto o "garantismo é sempre uma visão pessimista do poder como maléfico, quem quer que o detenha, porque exposto, de qualquer maneira, em ausência de limites e garantias, a degenerar em despotismo" 24 .

Assim, algumas questões, que malgrado sejam de suma importância e estejam sendo esquecidas, devem ser levantadas, tais como o rito das colaborações premiadas, a premiação tarifada e o duplo grau em caso de recusa, além da formalidade do rito de formulação de tais acordos.

No ponto, o atual cenário é caótico (e fértil para condutas desviantes), uma vez que não há rito específico para a formulação de pedido de colaboração premiada. Não há legislação alguma prevendo o modus operandi que a parte interessada em colaborar em prol do benefício deve adotar para propor o acordo ao Poder Público.

Nesse sentido, inclusive, a crítica encontra respaldo na doutrina:

Diferentemente do pentitismo, a delação no molde brasileiro carece de previsão acerca de seu procedimento, deixando para a doutrina e a jurisprudência essa difícil missão. É nessa seara de incertezas que alguns problemas surgem, como bem observa a Procuradora Regional da República Carla Veríssimo de Carli, ao narrar que, em vista disso, soluções diversas podem ser dadas para um mesmo caso, a depender do juiz. Como exemplos, a autora traz os seguintes questionamentos práticos acerca da modalidade premial: quem poderá propô-la? Necessária a concordância do Ministério Público? Até quando poderá ser realizada? Como deve ser feito o controle do acordo? Dentre várias outras dúvidas percebidas na práxis ${ }^{25}$.

${ }^{23}$ FERRAJOLI, Luigi. Direito e razão: teoria do garantismo penal. 3. ed. Tradução por SIZA, Ana Paulo Zomer; CHOUKR, Fauzi Hassan; TAVARES, Juares; GOMES, Luiz Flávio. São Paulo: Revista dos Tribunais, 2010, p. 816.

${ }^{24}$ FERRAJOLI, Luigi. Direito e razão: teoria do garantismo penal. 3. ed. Tradução por SIZA, Ana Paulo Zomer; CHOUKR, Fauzi Hassan; TAVARES, Juares; GOMES, Luiz Flávio. São Paulo: Revista dos Tribunais, 2010, p. 816.

${ }^{25}$ NASCIMENTO, Vanessa Urquiola do. A delação premiada no Brasil: críticas à ausência de procedimento legal pensadas a partir do exame da jurisprudência dos tribunais superiores. Disponível em <http://editora.pucrs.br/anais/cienciascriminais/III/3.pdf>. Acesso em 05 ago. 2019, p. 11. 
Ademais, não há qualquer previsão de quantidade/qualidade da colaboração e benefício obtidos, exceto no que tange ao art. $4^{\circ}$ da Lei 12.850/2013 - que, na prática, virou letra morta -, podendo a autoridade, eventualmente, aceitar um acordo não tão bom para perseguir determinado agente ou, por outro lado, não o aceitar para blindá-lo, violando, claramente, os princípios republicanos e de impessoalidade.

Por fim, malgrado não se esteja a falar de via jurisdicional propriamente dita (quando da formulação dos acordos), fato é que deve, sim, ser assegurado àquele que busque $\mathrm{o}$ acordo o direito ao duplo grau, tanto em respeito ao que alude o art. 8.2.h do Pacto de San José da Costa Rica (Dec. 678/92), quanto em razão do duplo grau administrativo (pluralidade de instâncias) ${ }^{26}$.

Assim, recusando-se o Promotor, o Procurador ou o Delegado natural do caso a firmar o acordo, deve ser cabível à parte que se sentir prejudicada recurso hierárquico dentro da própria instituição, a fim de que seja possível o controle dos que exerçam os poderes públicos.

Sobre o assunto, inclusive, bem assentou o Supremo Tribunal Federal no Mandado de Segurança 3327:

O ministro Gilmar Mendes acompanhou o voto do relator, mas, à guisa de obiter dictum, assentou premissas ao modelo de colaboração premiada brasileiro diante de omissões relevantes na legislação pertinente. As premissas foram endossadas pelos ministros Celso de Mello e Ricardo Lewandowski.

Para o ministro Gilmar Mendes, a negativa de realização do acordo por parte do órgão acusador deve ser devidamente motivada e orientada pelos critérios definidos em lei. Essa recusa também pode ser objeto de controle por órgão superior no âmbito do ministério público, por aplicação analógica do art. 28 do CPP. Ademais, informações ou elementos produzidos por investigados em negociações de acordo de colaboração premiada não formalizado não podem ser utilizadas na persecução penal. Por fim, o juiz, na sentença, pode

\footnotetext{
${ }^{26}$ DI PIETRO, Maria Sylvia Zanella. Direito Administrativo. 27. ed. São Paulo: Atlas, 2014, p. 707-8.

${ }^{27}$ BRASIL. Supremo Tribunal Federal. Mandado de Segurança n ${ }^{\circ} 35693$, AgR/DF. Rela- tor: Ministro Edson Fachin. Brasília, DF, 28 de maio de 2019. Diário Oficial da União. Brasília.
} 
conceder benefício ao investigado mesmo sem prévia homologação de acordo de colaboração premiada ${ }^{28}$.

Basicamente, portanto, o que há de ser mudado é a matriz da questão, ou seja, a existência abusiva de espaços de poderes discricionários, sob pena de apenas mudarmos o problema de local, ao invés de corrigi-lo.

\section{Considerações finais}

Ao concluir o presente artigo, após análise do fenômeno da $m a$ crocriminalidade enquanto estrutura, estruturada e estruturante, das práticas cotidianas que envolvem o poder, é visível a compreensão de que os espaços de poder arbitrário e discricionário tendem a possibilitar as práticas macrocriminosas.

Nesse sentido, a partir da análise das práticas cotidianas macrocriminosas, denota-se que estas são, em suma, formas de indivíduos maximizarem seus próprios capitais, políticos e econômicos, o que fazem em detrimento dos princípios da moralidade e, sobretudo, da impessoalidade.

Ademais, restou visualizado que a macrocriminalidade, diversamente da microcriminalidade, onde há um sujeito passivo bem definido, possui como alvo a coletividade, afetando direitos difusos e coletivos, sendo sobremaneira dificultosa a ciência do cometimento de tais ilícitos, inclusive pelas autoridades responsáveis pela persecução penal.

Desse modo, soa de bom alvitre a utilização de institutos que visam premiar os agentes que colaborem com a elucidação de práticas delituosas, tais como a delação premiada, whistleblower, entre outros.

Contudo, fato é que o combate à macrocriminalidade não pode ter o condão de subsidiar o aparecimento de espaços de poder discricionário, sob pena de haver apenas uma mudança do local fértil para o aparecimento de estruturas macrocriminosas, por meio do desvio aos princípios da moralidade e da impessoalidade.

Portanto, ao fim e ao cabo, pode-se perceber que o combate das práticas macrocriminosas passa, inexoravelmente, pela diminuição dos es-

${ }^{28}$ BRASIL. Supremo Tribunal Federal. INFOMATIVO 942. a2019. Disponível em: <http://www.stf.jus.br/arquivo/informativo/documento/informativo942.htm\#Acordo $\% 20 \mathrm{de} \% 20$ colabora $\%$ C $3 \%$ A7\%C3\%A3o\%20premiada $\% 20 \mathrm{e} \% 20$ aus $\%$ C $3 \%$ AAncia $\% 20$ de\%20direito\%201\%C3\%ADquido\%20e\%20certo>. Acesso em: 22 ago. 2019. 
paços de sua existência, quais sejam, os espaços de poder arbitrário e discricionário, devendo todo poder ser limitado e racionalizado.

Nesse compasso, a par da importância de institutos de colaboração premiada, deve-se pensar não mais "se" esses institutos devem existir, mas, sim "como", devem existir.

Assim, a discussão mais profícua do tema passa(ria) necessariamente pelas formas de controle (eliminação de espaços discricionários de poder) nas colaborações, tais como: tarifação da (redução de) pena em relação ao montante da organização entregue ou do quantum recuperado; dos requisitos objetivos e subjetivos para realização de um acordo, que deverá, no caso, passar a ser direito subjetivo da parte; direito ao duplo grau administrativo (colegiado) para o caso de indeferimento do benefícios nas instâncias que podem firmá-lo e; primeiramente, um rito legal (sim, criado pelo Poder Legislativo) para a forma de realização (pedido, trâmite, recurso administrativo, etc.) de acordos de colaboração. Cada uma destas medidas passível de um trabalho próprio.

Dessarte, malgrado tenha-se percebido a macrocriminalidade enquanto prática sistêmica e estrutural, a discussão sobre as formas de eliminação dessa estrutura (ainda) alongar-se-á, razão pela qual o estudo do tema em questão se mostra tão relevante.

\section{Referências}

BASTOS, Larissa. Crime aconteceu em 2014 e foi denunciado pelo Ministério Público; pena foi fixada em 12 anos e três meses. Disponível em <https://gazetaweb.globo.com/portal/noticia/2019/04/vereador-e-condenado-a-prisao-por-oferecer-sexo-a-menor-em-troca-de-favores_74281. php>. Acesso em: 16 de agosto de 2019.

BORGES, Manoela. Cassado mandato do vereador Cláudio Duarte (PSL), em plenário na Câmara Municipal de BH. Disponível em < https://g1.globo.com/mg/minas-gerais/noticia/2019/08/01/cassado-mandato-do-vereador-claudio-duarte-psl-em-plenario-na-camara-municipal-de-belo-horizonte.ghtml>. Acesso em: 16 de agosto de 2019.

BOURDIEU, Pierre. Choses dites. Paris: Les Éditions de Minuit, 1987, p. 33; Bourdieu, Pierre. Questions de sociologie. Paris: Les Éditions de Minuit, 1984, 1984.

. O poder simbólico. Lisboa: Difusão Editorial, 1989. 
Razões práticas: sobre a teoria da ação. Tradução Mariza Corrêa. São Paulo: Papirus, 1996.

BRASIL. Supremo Tribunal Federal. Inquérito $n^{\circ}-4435$. Relator: Ministro Marco Aurélio. Brasília, DF, 14 de março de 2019. Diário Oficial da União.

. Mandado de Segurança nํ35693, AgR/DF. Relator: Ministro Edson Fachin. Brasília, DF, 28 de maio de 2019. Diário Oficial da União. Brasília.

. INFORMATIVO 942. 2019. Disponível em: <http://www.stf. jus.br/arquivo/informativo/documento/informativo942.htm\#Acordo\%20 de $\% 20$ colabora $\%$ C3\%A7\%C3\%A3o\%20premiada $\% 20 \mathrm{e} \% 20$ aus\%C3\%AAncia\%20de\%20direito\%201\%C3\%ADquido\%20e\%20certo>. Acesso em: 22 ago. 2019.

CIRINO DOS SANTOS, Juarez. Direito penal parte geral. 5. edição. Florianópolis: Conceito Editorial, 2012.

DI PIETRO, Maria Sylvia Zanella. Direito Administrativo. 27. ed. São Paulo: Atlas, 2014.

FERRAJOLI, Luigi. Direito e razão: teoria do garantismo penal. 3. ed. Tradução por SIZA, Ana Paulo Zomer; CHOUKR, Fauzi Hassan; TAVARES, Juares; GOMES, Luiz Flávio. São Paulo: Revista dos Tribunais, 2010.

GOLDSCHIMIDT, James. Problemas jurídicos y políticos del proceso penal, Buenos Aires: AJEA, 1936.

GONÇALVES, Victor Eduardo Rios; BALTAZAR JÚNIOR, José Paulo. Legislação penal especial. 2. ed. São Paulo: Saraiva, 2016.

MARX, Karl. Contribuición a la crítica de la economia politica. La Habana, Instituto do Libro, 1975.

NASCIMENTO, Vanessa Urquiola do. A delação premiada no Brasil: críticas à ausência de procedimento legal pensadas a partir do exame da jurisprudência dos tribunais superiores. Disponível em <http://editora.pucrs.br/ anais/cienciascriminais/III/3.pdf>. Acesso em: 05 ago. 2019.

PASOLD, Cesar Luiz. Metodologia da Pesquisa Jurídica: Teoria e Prática. 12 ed. rev. São Paulo: Conceito Editorial, 2011.

\section{Prática da Pesquisa Jurídica e metodologia da pesquisa jurí-}

dica. Florianópolis: OAB/SC Editora, 2007.

SANTOS, Juarez Cirino dos. Direito Penal: parte geral. 5. ed. Santa Catarina: Conceito, 2012. 
VASSALLO, Luiz; MACEDO, Fausto. Promotoria não acredita que Quei-roz possa ser o líder da organização criminosa. Disponível em <http://

www.tribunadainternet.com.br/promotoria-nao-acredita-que-queiroz-possa-ser-o-lider-da-organizacao-criminosa/ >. Acesso em: 16 de agosto de 2019.

José Edilson da Cunha Fontenelle Neto - Mestre em Ciência Jurídica pela Universidade do Vale do Itajaí - UNIVALI, mestre em Direito da União Europeia pela Universidade do Minho - UMINHO/PT, especialista pós-graduado em direito penal e criminologia peloInstituto de Criminologia e Política Criminal ICPC/UNINTER. Graduado em Direito pela Universidade da Região de Joinville UNIVILLE. Professor de Direito Penal e deDireito Processual Penal na Universidade da Região de Joinville - UNIVILLE. Advogado. 
